used as light filters. Thus for Lumière's " B" plates we must have a bright chromium green, a deep pot-green glass, together with aurantia ; while for Lumière's "A," we should use a red light consisting, for instance, of aurantia, naphthol yellow and fuchsin films. For Thomas's plates a faint green or a fairly bright red glass with a strong tint of aurantia dye might be employed. Edward's snap-shot isochromatic and rapid spectrum plates require the quality of the filter light to be very pure.

\section{THE CHEMICAL SOCIETY'S BANQUET TO PAST-PRESIDENTS.}

$\mathrm{R}$ EFERENCE has already been made to the banquet given on November I I to Sir J. Henry Gilbert, Sir Edward Frankland, K.C.B., Prof. W. Odling, Sir. Frederick Abel, Bart., K.C.B., Prof. A. W. Williamson, and Dr. J. H. Gladstone, Past-Presidents of the Chemical Society, who have been Fellows of the Society for fifty years or more. The idea of expressing in this way the high regard in which men of science hold the work of these distinguished chemists was an excellent one, and it was well carried out. The large number of congratulatory telegrams and communications received on the day of the banquet from every country where the science of chemistry is cultivated showed that the whole civilised world was in sympathy with the object of the banquet. Communications were received from France, Holland, Belgium, Germany, Sweden, Russia, Austria, the United States, and several other countries. Prof. Friedel wrote: "I should have been happy to associate myself with the Chemical Society in doing honour to these veterans of science. I have the honour to be the friend of most of them, and the beneficent action they have exerted on Chemical Science cannot be esteemed too highly. They form the finest phalanx of the Fathers of our science which exists in any country. With these sentiments you will understand the liveliness of nuy regret to be able to take part from afar and in spirit only in the honour paid them." At a meeting of the Russian Chemical Society the following was passed : "That the Society avail itself of the exceptional opportunity of being able to congratulate conjointly Sir Joseph Henry Gilbert, Sir Edward Frankland, Prof. Odling, Sir F. A. Abel, Dr. A. W. Williamson, and Dr. J. H. Gladstone, whose distinguished services during half a century stand out as a model for all investigators in chemical science, and also express the wish to see the further results of their labours in the annals of science for many years to come." A telegram from the German Chemical Society contained the message: "The sister Society sends both Jubilee congratulations and greetings to the Jubilee celebration of the Presidents of the Chemical Society, Gilbert, Frankland, Odling, Abel, Williamson, and Gladstone." These messages show that the distinguished men to whom the banquet was offered are held in the highest esteem in all places where chemical studies are carried on.

We regret that the limitations of space will not permit us to print the speech in which the President, Prof. Dewar, who occupied the chair at the banquet, alluded to the work of the six Past-Presidents, nor can we find room for any speeches other than those in which these distinguished men replied to the toast in their honour.

Sir J. Henry Gilbert said :-_" After the extremely flattering and eloquent terms in which our President has referred to the work of the six Past-Presidents of the Society who are so highly honoured to-night, it is surely a difficult task to say anything in response. I feel that any words of mine would be entirely inadequate; and I must, I think, fall back on what I was intending to say, and give a little personal history of the early times of the Society. You are aware, most of you, that I am to night in the position of the senior of the Past-Presidents, in consequence of the death of Lord Playfair. He was, as you know, one of the founders of the Society, and, before he died, the only survivor of those fonnders. I myself came in within three months of the foundation, and so had some knowledge of the Society's early doings. In fact, before I was really admitted to the Society, under the influence of the late Professor Graham, I undertook the translation of a paper by Redtenbacher and Liebig on 'The Atomic Weight of Carbon,' and that paper occupies eighteen pages in the first volume of the Society's "Memoirs." I should say that, less than a fortnight ago, I received a letter from Lady Playfair, just before she left to visit her friends in America, in which she said with what interest he had looked. forward to being present at the banquet appointed for June-but that was not to be. I first made the acquaintance of Playfair in Liebig's Laboratory at Giessen, the year before the establishment of this Society, that is, in I840. Playfair was at that time very busily occupied in translating the memorable work of Liebig, 'Organic Chemistry in its Applications to Agriculture and Physiology'; and before the session was over he left for this country with Liebig, who was to present the substance of that work as a report to the British Association at Glasgow in September. You may be interested to know who there were from this country in Liebig's laboratory at that time. Besides Playfair and myself, there were Dr. William Allen Miller, afterwards professor of chemistry at King's College; Dr. Stenhouse, who has contributed so much to the Journal of this Society; Dr. Angus Smith; and, lastly, Dr. Edward Schunck. He and I are, I believe, the only survivors of that time among those from England who were with Liebig then. Of the Germans who were there, some of the names you will probably remember. There were Heinrich Will, Varrentrapp, Redtenbacher, Hermann Kopp, Scherer, Bromeis, Boeckmann, and others, of various nationalities; but I believe that not one of these survives at present. Schunck joined the Society early in 1842 , and he from that time to this has devoted himself to scientific investigation. He built a laboratory, and a museum devoted especially to specimens of organic bodies, in his own grounds on the other side of Manchester, where he still lives. He was, in fact, the oldest member of the Society, I believe, except Playfair and myself. He has worked indefatigably ever since; but I am very sorry to say he is not able to be here to-night, having had an attack of bronchitis, which renders it impossible, though it would have given him great pleasure to be present. Referring to that time at Giessen, I may say that Playfair, Stenhouse, and myself, each took our degree then; and Playfair, though joining with us, having gone with Liebig, the responsibility was left with Stenhouse and myself to give the usual supper to the other students of the laboratory, and a few distinguished guests, among whom was Bunsen, who was then at Marburg; and who, I am glad to learn from Sir Henry Roscoe, is still well. Sten. house was much my senior. We had a large and lively party, but Stenhouse did not enjoy that sort of thing very much, and when the last bottle of champagne was opened, he said: 'Now, Gilbert, I shall leave you to it,' and away he went. That was, however, not near the end of the evening. They stayed a very long time, and we did not exchange the smoky atmosphere of the supper-room for the clearer air outside until early morning. We then went round the boulevards of the little town, the Germans singing students' songs, and coming in time to the hotel where Stenhouse lodged, we serenaded him from the outside. Then some one tried the door, and finding it unfastened, the whole party went up, lighted candles, and serenaded him in bed. Next morning there was a very capital caricature brought out, showing Stenhouse's rather long nose pointing in one direction, and his longer nightcap in the other. But this is enough of this kind of history, and I must now turn to rather more serious matters. It was in 1843 that I became associated with Mr. (now Sir John) Lawes in agricultural investigation - a collaboration which has now extended over more than fifty-five years. As you all know, however rude may be some of the methods of the art of agriculture, the investigation of the principles underlying its practices involves a wide range of scientific inquiry. It inyolves the chemistry of the atmosphere, of the soil, of vegetation, and of animal life and growth. That is to say, besides chemistry, it involves meteorology, botany, vegetable physiology, and animal physiology, to some extent. It is impossible to be a specialist in so many subjects, particularly in these days, and I can only say that in venturing to deal with these other branches of science we have taken great care to avoid mistakes. The wide range of the investigations must be accepted as some explanation of the fact that we have not contributed more of the results to the Chemical Society. Many of them being connected largely with other branches of science, have been, recorded in other than purely chemical journals; whilst those having a more directly practical bearing have been published in the Journal of the Royal Agricultural Society, or in other agricultural publications-the Rothamsted papers now numbering considerably more than roo. But we feel that, however long or short may be the time that we shall still work

NO. I 5 I 7 , VOL. 59] 
together, we shall perhaps have done as much in opening up as in solving problems; and that we shall certainly leave plenty for our successors to do. In conclusion, considering that there still remain five of your honoured guests to speak, this is all I will say of my own career, and I will only now ask you, Mr. President, the Council, and the Fellows of the Chemical Society, to believe that I esteem very highly the great honour you have conferred upon me to-night."

Sir Edward Frankland-" Allow me to thank you, Mr. President, and the Council of the Chemical Society for this delightful entertainment which you have prepared for the Past-Presidents who have attained Jubilee rank. It was a generous, unique, and happy idea, which I feel sure we all heartily appreciate, not only as we sit at your hospitable board, but also when we reflect on the kind feelings which led to the conception of that idea. There used to be a phrenological organ entitled 'love of approbation,' and whether there is or is not a part of the brain told off to perform this function, I trust that chemists are not behind the rest of humanity in appreciating such an honour as you have conferred upon us on this auspicious occasion. Nothing could be more agreeable than thus meeting so many colleagues who are worthily keeping up the high reputation of the Chemical Society. There is but one drawback to our enjoyment, and it has been very feelingly alluded to by Sir Henry Gilbert, namely, that one who so recentlystood at the head of our Past-Presidents should not still be present amongst us. In the lamented death of Lord Playfair, chemistry and science generally have sustained an immeasurable loss; for he was a binding link between science and the State, alway's ready to fight for the cause of truth against prejudice and ignorance, and never ceasing in his efforts to bring home to our rulers the vast importance of the applications of science to the progress, health and prosperity ot the nation. As one of his first pupils, and after a life-long friendship, I may be permitted to testify that his energy in this cause was prompted by sincere convictions and not by political exigencies. Had Playfair lived a few months longer, we should never have had the misfortune to make the acquaintance of that new variety of Homo sapiens the 'conscientious objector,' who is just now giving so much trouble to our magistrates. This is not a time to sketch, even in merest outline, the epoch-making work of the Society, but I may at least state my conviction that it will be found, on comparing the volumes of our Transactions with those of the corresponding societies of other lands, that, considering the number of workers in each case, England is not behind any other nation in research work, and this in spite of the almost total absence of that lavish State aid which nearly every other civilised nation enjoys. In view of the vast number of discoveries pouring out from chemical laboratories, I hear it suggested that the day is not far distant when there will be nothing left to discover, when all the elements in the cosmos shall have been captured and fitted into the periodic system of Newlands and Mendeléeff, when there is not one more gas in the atmosphere left to be detected, and every element and group of elements shall have its ortho-, para-, and meta-position assigned to it. What will then remain to be done? Fortunately for investigators, we shall still be only as children gathering pebbles on the shore of the great ocean of knowledge. As yet we have only found the big boulders. To change the metaphor, chemistry now occupies the position of geography a century ago. The enormous number of chemical compounds are like so many islands, their latitude and longitude ascertained with precision, but on which the foot of man has not been put down, whilst their animals, plants, and minerals have never been exploited. When the ideal state of knowledge has been attained, chemists will perhaps find time to explore this vast archipelago, in which, there is no doubt, many interesting discoveries await those who shall undertake the task. Who can set a limit to the usefulness of these explorations? Even the most unpromising compounds may turn out valuable prizes When aniline, chloroform, and carbolic acid were discovered, who could have predicted the revolutions in the arts and surgery which these bodies were destined to produce! They were but as desert islands until they attracted the attention of Hofmann, Perkin, James Simpson, and Lister. As chemists, I believe we have a noble future before us. Chemistry is distinguished from all other branches of knowledge as the helpmate of nearly every other science. The geologist, the botanist, and the physiologist find no thoroughfare unless they call in the help of the chemist. As soon as the physicist breaks into a molecule, he is trespassing on our domain. The bacteriologist has found that it is not the waggling of the tail of a pathogenic microbe that is the most important feature of its history, but that the chemical compounds which it secretes demand his closest attention. Even the astronomer has already to sit at the feet of the chemist! Thirty-three years ago, when our worthy President was but a youth, there was once a dinner party composed chiefly of chemists held at the 'Albion.' A few are still living--among them being Sir F. Abel, Prof. Odling, and myself. In an after-dinner speech on that occasion, my friend Abel is reported to have expressed himself in blank verse as follows (I hope he will forgive me, at this distance of time, for appropriating his words to my own use):

" 'Looking to right and to left, I see many faces around me,

Faces so old and familiar I feel once again at the College

Testing, as in former times, for chlorine with nitrate of silver,

Gazing with youthful delight at crystals just hatched in a beaker,

Yearning o'er aniline drops distilling from crystal alembic.

$0 !$ my dear friends, one and all, we have toiled up a difficult pathway

Some are low down on the hill, and others are near to the summit.

Let us remember the past and forget not our absent companions;

Fortune mary come to us all; but youth will return to us never!',

Prof. Odling :- "I do not know that I can better commence the few observations I propose to make to you than by following in the wake of my predecessor, Sir Edward Frankland, and saying that it is no less a great pleasure than my bounden duty to express to you, Mr. President, and to the Council and Fellows of the Society, my heartfelt thanks for the great compliment that you have paid to my colleagues and myself on this long-to-beremembered occasion. Speaking, however, for myself personally, it is not the first time that I have had evidenced to me the kindly feeling of the Chemical Society. On the occasion of my retirement from the Secretaryship in $\mathbf{1 8 6 9 ,}$, had also the special honour done me of being entertained at a dinner by the Society and $I$ also received a further token of their goodwill in the form of a capacious loving cup of no inconsiderable value in itself, but of far greater value as a perpetual mark of the kind feeling towards me of those with whom I had been for so many years so intimately connected. Those of us whom you entertain this evening have for a long period of time, as Sir Henry Gilbert and Sir Edward Frankland have already remarked, been associated with one another in common pursuits and enjoyments; and if there is one thing more than another that enhances to me the gratification of this meeting, it is the pleasure of finding myself associated still with my old friends and colleagues, Gilbert and Frankland and Williamson and Gladstone, and my earliest friend of all, Sir Frederick Abel. We have been concerned with one another in a large number of undertakings, and for a long period of time have been accustomed to hear one another's voices as well upon festive as upon scientific occasions. But we have not been accustomed to hear them in exactly the order they have been arranged for this evening. I have always looked upon myself, not as a precursor, but as a follower of Williamson. It has been my pride to reckon myself one of his adopted pupils-a disciple of his ideas more perhaps than many of those who were his actual pupils. He was always very decided in his notions. Sometimes, indeed, I turned a little restive, but was always soon pulled up into form again-sometimes more abruptly, perhaps, than was quite agreeable at the moment. At one time I laboured under the sad suspicion of being a little unsound as to the Atomic Theory. Well, perhaps I was not altogether so stalwart in its defence as I ought to have been; but I can assure you that I was never really guilty of so reprehensible a heresy as that which was attributed to me.

"You are doing us honour here this evening not so much, or not only, as students of the science of chemistry, but also as Past-Presidents of the Chemical Society. As ancients of that Society, we may all of us perhaps be permitted to talk a little about ourselves without incurring the imputation of egoism, and also to talk a little about old times without incurring the reproach, after our fifty years' fellowship, of senile garrulity. At the period during which I acted as one of the Secretaries of the Society, and my colleague, Prof. Redwood, concerned hin. self mostly with the business department of our affairs, the Chemical Society had not developed very far its function as a publishing agency, and as a consequence, even for that little prolific time, we did not get our fair share of important papers communicated at first hand to our meetings. But if we did not receive elaborate communications, we enjoyed the benefit of elaborate discussions ; and there was no new class of compounds,

NO. I 517, VOL. 59] 
no newly propounded doctrine, no new reaction which was not submitted to our keen examination and controversy. The subjects of several of those controversies, and even the fashion of them, still linger in one's memory. I need scarcely say that chemical theory came in for a large share of our attention. The molecular weights of water and carbonic acid, the atomic weights of oxygen and carbon, and, above all, the then newly introduced idea of polyatomic radicles, were keenly discussed. We were a little too late for the interesting question as to whether compound radicles could possibly be oxygenous; but still, radicles were predominant at that time in chemical science, and reigned with undisputed sway over the whole domain of organic chemistry. One cannot but reflect how fleeting has been their reign. The doctrine of radicles has now sunk to an entirely subordinate position in chemistry, not unlike, may I venture to say, the subordinate position into which radical doctrines have fallen in a different sphere. There was one particular controversy I remember very well, and am sure Frankland will remember also. It was of this kind: whether the bodies called ethyl and methyl were really ethyl and methyl at all, or something else. Well, a question of that kind in thuse unsophisticated days had to be answered definitely by a plain aye or no. There was no loophole for escape or trimming, no possibility of saying that the one answer was just as true as the other, according to the point of view taken; nor was there existent in that period of innocence, for the solution of yet more puzzling problems, what we know now by the name of tantomerism, by which we learn that a body is, and at the same time is not, what it is alleged to be ; that it is sometimes one thing and sometimes another, and sometimes both together, and yet preserves its individual chemical entity. In those days the principal provider of chemical material for our meetings was far and away Hofmann. $\mathrm{He}$ was in the habit of sending his multitudinous papers to the Royal Society for publication but he gave us the advantage of his presence and his personal disquisitions; and I would appeal to all in this room who had the advantage of seeing him to say if they can possibly forget his appearances at the blackboard of the Chemical Society, and the enthusiasm and lucidity of his expositions of different points of chemical constitution, enlivened as they were by that extraordinary display of vivacity so inconsisten with the quiet phlegm we are in the habit of attributing to those of his nationality. But, despite the productiveness of Hofmann, still there were evenings on which something else was required; and then it behoved the Secretary to search far and wide for material to bring before the meeting of chemists who, with Greek-like avidity, were always clamorous for 'some new thing.' At that period the activity of the Giessen school was somewhat on the decline, and we looked for novelties in chemistry, as for novelties in mantles and millinery, to Paris. We had for our consideration the acidic ammonias of Gerhardt and the diatomic glycols of Wurtz, and the production of alcohol without the aid of either sugar or yeast, by Berthelot ; and many other remarkable contributions to the knowledge of the day But our friends across the water, with so much-so very much - justly due to them, nevertheless did manifest now and then a tendency to appropriate to themselves what did not altogether belong to them; and in this the country of Black and Priestley and Cavendish and Dalton and Davy, we were astonished one fine morning at being informed that 'la Chimie est une science française.' But even with the productiveness of Hofmann and the searchings of the Secretary, it did sometimes happen that our bill of fare was a little meagre. But what of that? Those were supper-eating days, and a meeting rendered brief by want of pabulum could always be supplemented by a prolonged and substantial, and, I may add, a musical, meal at a then well-known resort not far from Covent Garden; and when it happened, as it did sometimes, that our proceedings were not so exhilarating as they should have been, when divine philosophy had proved less charming than its wont, Hofmann, despite the abundant supply of tea and coffee of excellent quality, would, with a burst of inspiration, thrust forth his right hand and say: 'I will tell you, we will have a punch!'

"But the Chemical Society has a future to look forward to, as well as a past to look back upon. At the Jubilee of the Society some seven or eight years ago, it devolved upon me to give an account within the short period of a quarter of an hour -I believe I occupied twenty minutes-of the progress of chemical science during the preceding fifty years. But to-day is also a Jubilee or almost so, the Jubilee of our incorporation by Royal Charter, which, in the then days of our insignificance, Playfair did so much to obtain for us. Now, on this diamond Jubilee, I ask you how many minutes will you give me to lay before you a forecast of the chemical progress that may be expected to take place within the next fifty years? I will only venture to say that, judging by the number and activity and intellectual gifts of the workers of the present day, we may feel assured that the achievements of English chemistry and the progress of the Chemical Society in the past will be as a mere nothing to the brilliancy which they will attain to in the future."

Sir Frederick . Abel-" "Sir Edward Frankland has out of his vast stores of knowledge recalled a fact of which I confess I was ignorant, that in years past $I$ indulged a poetic fancy. I only wish I might now be inspired in order to find words to express on behalf of myself and my old friends our appreciation of this glorious reception which you have given us. The Chemical Society is endeared to me in many ways. Among the epochs of a sonewhat long career of ceaseless activity, that which connected me intimately with the work of the Society is one of those which I recall with the greatest pleasure and satis. faction. And it so happens that the years of my connection with the Society in various functions were years in which some of the most memorable events in its annals occurred. As Treasurer, it was my privilege to arrange with the illustrious chemist and brilliant orator, Jean Baptiste Dumas, for the delivery of the first of those memorable lectures which were given through the agency of the Chemical Society in honour of the memory of Michael Faraday. While I was Treasurer, the volume of the Journal of the Society, which was then of modest and slender dimensions, nurtured by well digested extracts from foreign journals, speedily gained proportions unwieldy in character, so unwieldy, in fact, that the one volume split up into two before long. In the first year of my Presidency, the Research Fund, which was initiated in a modest manner by $\mathrm{Mr}$. Thomas Hyde Hills, was placed upon a firm and substantial basis through the generosity of one of the most respected of the Society's original members, Dr. Longstaff ; and in the second year in which I held that office, the somewhat revolutionary agitation which was persisted in by a not unimportant section of the younger Fellows of the Society, an agitation which, by the way, has been imitated since-led to earnest deliberation and consultation between the Council and some of its chosen members outside the Council, which resulted in the birth of an institution now flourishing exceedingly, which has become the guardian of the best interests not only of the chemical profession but also of the public. I of course allude to the Institute of Chemistry of Great Britain and Ireland. When I look back to the early days when I first owned the proud title of F.C.S., and remember my attendance, in a small room at the Society of Arts, at the meetings of the Chemical Society, presided over in succession by William Brande and Phillips, the business being managed by George Fownes and Robert Warington, the founder of the Chemical Society, and the funds not very cleverly handled by dear old Robert Porrett, one of the most prominent forms that appears in my mind's eye is that of the favourite pupil of Liebig, my venerated master, Hofmann. In the very first years of the Society, Hofmann became the very life and soul of it. He was beloved by his English brethren directly he came among them, and for years he was by far the most prolific contributor, either himself or through his pupils, to the volumes of the Society. Pardon me if I have been tempted into reminiscences; it is difficult to avoid it at such a gathering as this. The welcome you have given to the veteran Past-Presidents will remain in their minds to their last day as one of the great joys of their lives. To the many old friends and colleagues whom I see around me-Past-Presidents who, as men of science, hold positions second to none, whose names are familiar as household words-to them I can wish no higher gratification than that they may live to experience the satisfaction of such an entertainment, and of such a graceful appreciation of their work, as has been the lot of your old Past-Presidents to-night."

Prof. A. W. Williamson- "I thank ycu, Mr. President, most heartily for the kindly words you have uttered in relation to me, and to my efforts for the advancement of chemistry. It is an immense satisfaction to me to see a man of your talents and vast acquirements placed in so influential a position as that which you so worthily occupy. But whilst thanking you I am

NO. I 517 , VOL. 59] 
bound to confess that I have been for some time past a most unworthy member of the Chemical Society. It happened that after a good many years of work in our Society, I had other matters of such importance claiming my time and attention, that I was unable to continue to work amongst my colleagues and friends in the Chemical Society.

"Before I came over in 1849 to work at University College, I had become acquainted in the Giessen Laboratory with that most remarkable man, August Wilhelm Hofmann, and I may mention a characteristic incident illustrating his earnest and steadfast devotion to his science. He had for a considerable time been working at derivatives of aniline, and in order to carry on these researches as effectively as possible, he prepared by the action of caustic potash on indigo about some two gallons of aniline. The product was placed in a big bottle on the mantelpiece in his bedroom, and the story goes that he used to stand and gaze at it for some time every morning and evening, and gloating over it with delight would think, 'what a number of splendid products I shall make out of this aniline!' The energy and devotion with which he followed up his work on the derivatives of aniline at the expense of many other researches which he might with advantage have followed up was such that he came to be talked of as the great worker on aniline, and Sir Benjamin Brodie somewhat prematurely wrote his epitaph in the following words, 'Hic jacet Aniline.' His researches extended, however, at an increasing rate into other and wider departments of chemistry, and his energy and enthusiasm were such as to make him the leading explorer in the domain of organic chemistry. Berzelius had been for a lengthened period the one great man in the domain of inorganic chemistry, which was the only part of the science which had been explored to any appreciable extent. When I saw the vast piles of knowledge which Hofmann was so rapidly accumulating in the new domain of chemistry, I felt, and ventured to say, that his masterly labours entitled him to be called the Berzelius of Organic Chemistry. I happened to be present at a meeting of the Chemical Society at which a young chemist read a paper in the presence of Hofmann on some theoretical matters of importance which had already engaged the attention of distinguished chemists. Hofmann did not enter into any particulars of the paper, but he gave vent to an outburst of heartfelt delight at the simple narrative which had been read. There are various incentives to work, but the most potent incentive to earnest and efficient work is probably the example of a man iike Hofmann, whose whole delight lay in mastering the truths of science, and in learning more and more particulars of the order of nature, and Hofmann possessed that power in a most eminent degree.

"We see in this grand hall an assemblage of chemists known by their earnest labours and valuable discoveries, and we are honoured by the presence of men of the highest distinction in other branches of science, as well as of leaders in the learned professions. It might not be unreasonable to believe that enthusiastic delight in the triumphs of chemical research is duly represented by some of the guests in this hall, and that the lively conversation which has been going on may not relate merely to high questions in juisprudence, medicine, or legislation, but that some samples of chemical enthusiasm may reach the ears of the learned representatives of other professions.

"I feel sure that at a future time we shall all look back with the highest pleasure upon this delightful evening, which we owe to the kindly exertions of our President and other leading members of the Society."

Dr. John Hall Gladstone- "It is a pleasant thing to look on the faces of so many friends with whom one has worked in olden times, with whose works one is well acquainted. Though, of course, there are many at the present time who come into the Society, and whom I can look to as budding philosophers : un fortunately, I do not know their names so well as their faces. The pleasure is not merely because we call ourselves chemists, but because there is a bond of union between us arising from the desire of discovering the wonderful secrets of the great cosmos of which we ourselves form part. There is a great difficulty in speaking to you this evening, because so much that I should have likeri to say has already been said by previous speakers. Still there are one or two things which, if you will permit me, I should like to bring before you. First of all, in your too flattering description, of myself and of my work-which makes me rather ashamed to stand up and speakthere was a point which I think calls for remark, and so I must venture upon that which characterises the speeches of all of us, a certain amount of early autobiography. I was exceedingly fond of science from a little child. My favourite science was geology, and also what could be seen in the microscope-infusoria, and other little objects we have heard of in later times. But, in choosing a profession, my father said geology was not a promising career, and recommended chemistry. I knew very little about it, but went to University College and studied under that admirable teacher, Professor Graham, and afterwards under Liebig. I suppose it was from Graham that I acquired the taste for the physical side of chemistry and its connection with heat, light, electricity, and other forces of nature. I looked out for a scientific position, and lectured at St. Thomas's Hospital for some time. made analyses, and considered myself a professional chemist It may be that circumstances have caused me to sink into the position of an amateur chemist, but my first intention was that of following chemistry as my protession in life. It has not been necessary to continue that; and I have had this advantage, that I could always keep in my laboratory a good, trained assistant, and thus, whilst I was engaged in other works and ways, and in endeavouring to extend the knowledge of chemistry and elementary science in our primary schools, the work still went on more or less under my immediate direction. I should like to have said something about the progress of chemistry during these past fifty years; but the subject is so enormous, and you yourself have touched upon it to such an extent and so well, that I need only allude to the fact that this great change of volume of chemistry has caused it to be necessary that we should specialise. Specialisation has its advantages, but also its disadvantages. One danger is that we may become narrowed in our views. So it would appear to be best to have a home somewhere or other, but to make occasional excursions in the neighbourhood, and take summer holidays so as to get our nerves braced up to work again at our own pet subjects. I must not touch upon other points, such as the relations of the physical forces to chemistry, or its useful applications, and the great value of chemical research for the welfare of mankind. These are subjects too large and important to enter upon at this late hour. It seems to me that while we are always increasing the mass of knowledge we possess, the space which we see to be bright becomes larger and larger, but there is beyond a dim nebulosity. It is our work to bring from that nebulosity something into the bright space, so that it becomes the property of the human race. But there is beyond this a region which we do not understand-infinite as far as we know-and our object is to increase that which is knowable, in the firm belief that it will be for the advantage of our fellow creatures. While I feel thankful for the joy that I have had in taking some part in these discoveries, I cannot look to have much more time given me for carrying on this work of investigation; but still, there may be a few threads of old research I may gather up, and in doing so I shall be greatly encouraged by the kind remarks of this evening, and the way in which our work has been received by the friends gathered around us."

\section{RECENT AND FOSSIL RHINOCEROSES.'}

PROF. OSBORN'S palæontological work is so painstaking, and his material is so rich, that all interested in the study of the evolutionary and distributional history of those remarkable Peristodactyles which may be included under the general title of Rhinoceroses, cannot fail to welcome the appearance of the elaborate and well-illustrated memoir before us. As at present planned, the complete memoir is to consist of no less than seven parts, two of which are contained in the present issue; so that until the whole appears, a suspension of judgment in regard to many points is due to the author.

Prof. Osborn is of opinion that the Rhinoceros-like Ungulates may be divided into the three families of Hyracodontide, Amynodontide, and Rhinocerotide. And as this arrangement tallies fairly well with the date of appearance and disappearance, and also with the relative specialisation of its various members, the general principle may be adopted. It must not, however, be supposed that either of the first two families are exclusively ancestral types of the third, as many of their representatives tended to specialise at a comparatively early period, and took an evolutionary line of their own. Some, for instance,

1 "The Extinct Rhinoceroses." By H. F. Osborn. Mem. Amer. Mus. Nat. Hist., vol. i. part iii., pp. 75-164, l'lates X11A-XX. (1898.)

NO. I 5 I 7, VOL. 59] 